\title{
The Effect of Nanolayer Thickness on the Structure and Properties of Multilayer TiN/MoN Coatings
}

\author{
A. D. Pogrebnjak*, V. M. Beresnev, O. V. Bondar, G. Abadias, P. Chartier, \\ B. A. Postol'nyi, A. A. Andreev, and O. V. Sobol' \\ Sumy State University, Sumy, Ukraine \\ Karazin National University of Kharkiv, Kharkiv, Ukraine \\ Institute P', University of Poitiers, Chasseneuil-Futuroscope, France \\ Kharkiv Institute of Physics and Technology, Kharkiv, Ukraine \\ National Technical University Kharkiv Polytechnic Institute, Kharkiv, Ukraine \\ *e-mail:alexp@i.ua \\ Received July 8, 2013
}

\begin{abstract}
The effect of nanolayer thickness on the structure and properties of nanocomposite multilayer TiN/MoN coatings is revealed. The multilayer (alternating) TiN/MoN coatings are prepared by the ArcPVD method. The selected thickness of the nanolayers is $2,10,20$, and $40 \mathrm{~nm}$. The formation of two phases- TiN (fcc) and $\gamma-\mathrm{Mo}_{2} \mathrm{~N}$-is found. The ratio of Ti and Mo concentrations varies with varying layer thickness. The maximum hardness value obtained for different thicknesses of the layers does not exceed 28$31 \mathrm{GPa}$. The stability of TiN/MoN during cutting and tribological tests is significantly higher than that of products with TiN coatings. The nanostructured multilayer coatings with layer thicknesses of 10 and $20 \mathrm{~nm}$ exhibit the lowest friction coefficient of 0.09-0.12.
\end{abstract}

DOI: $10.1134 / \mathrm{S} 1063785014030092$

Multilayer, multicomponent, and nanostructured coatings have recently provided a basis for solving problems of protection of products with different functional purposes, such as hardness, wear resistance, corrosion resistance to high temperature oxidation, fatigue, etc. [1-4]. It is well known that coatings of TiN [3-6] and MoN [1, 2] provide wear protection (being deposited on cutting tools for hard-to-machine parts); in some cases, they protect against corrosion. However, the thermal stability of these coatings (single-layer coatings of TiN and MoN) is not very high. At a temperature of $550-600^{\circ} \mathrm{C}$, the coatings begin to oxidize and their hardness sharply decreases [7, 8]. Therefore, the development of TiN/MoN-based multilayer nanostructured coatings with high mechanical and tribological properties for increasing the range of protective functions is a relevant task of solid-state physics and materials science. In this regard, it is of interest to study nanostructured layers composed of a combination of alternating $\mathrm{TiN}$ and $\mathrm{MoN}$ layers and their structure and properties under varying thickness of the layers of these nitrides from 2 to $40 \mathrm{~nm}$.

Nanostructured multilayer (alternating) TiN/MoN coatings were deposited using a Bulat-6 vacuum arc setup with two evaporators ( $\mathrm{Ti}$ and $\mathrm{Mo}$ ) [2]. The setup is equipped with a dc voltage supply (5$1000 \mathrm{~V}$ ) and a pulse voltage generator with an adjustable pulse amplitude in a range of $0.5-2 \mathrm{kV}$ and a repetition rate of $5-7 \mathrm{kHz}$. The deposited nanolayers (of
TiN and MoN) had a thickness of about 2, 10, 20, and $40 \mathrm{~nm}$; the total coating thickness was $6.8-8.2 \mu \mathrm{m}$.

Complete information on the elemental composition of the coatings was derived on a Rutherford backscattering (RBS) setup using $1.5-\mathrm{MeV} \mathrm{He}^{+}$ions (a scattering angle of $\theta=170^{\circ}$, normal incidence of probing ions on the samples, an energy resolution of the detector of $16 \mathrm{keV}$, and a dose of helium ions of $5 \mu \mathrm{C})[8,11]$. A proton microbeam ( $\mu$-PIXE) with an initial energy of $1.4 \mathrm{MeV}$ was used on the basis of an IAP electrostatic accelerator (Sumy) with a beam size of $0.5 \mu \mathrm{m}$ (a charge of $3 \times 10^{-10} \mathrm{C} /$ pixel, a $50 \times 50$-scan pattern, and a scanning pitch of $0.5 \mu \mathrm{m}$ ) [10].

The microstructure and elemental composition of the coatings were studied using a few electron-ion scanning microscopes (Quanta 200 3D, Quanta 600 FE-SEM) equipped with a PEGASUS $2000 \mathrm{X}$-ray detector system. In addition, a JEOL-7001F scanning electron microscope with an EDX microanalyzer (Japan) was used. The structure and phase composition of the coatings were studied by XRD analysis (Bruker Advanced 8) using $\mathrm{Cu} K_{\alpha}$ radiation. Hardness and Young modulus were measured using a CSM instrument (Switzerland). Tribological studies were conducted using a Revetest scratch testing instrument (CSM Instruments) by measuring friction coefficient $\mu$, wear resistance, and acoustic emission induced by indentation of a Rockwell-C pyramid. Transverse sections were prepared to analyze the multilayer coatings 


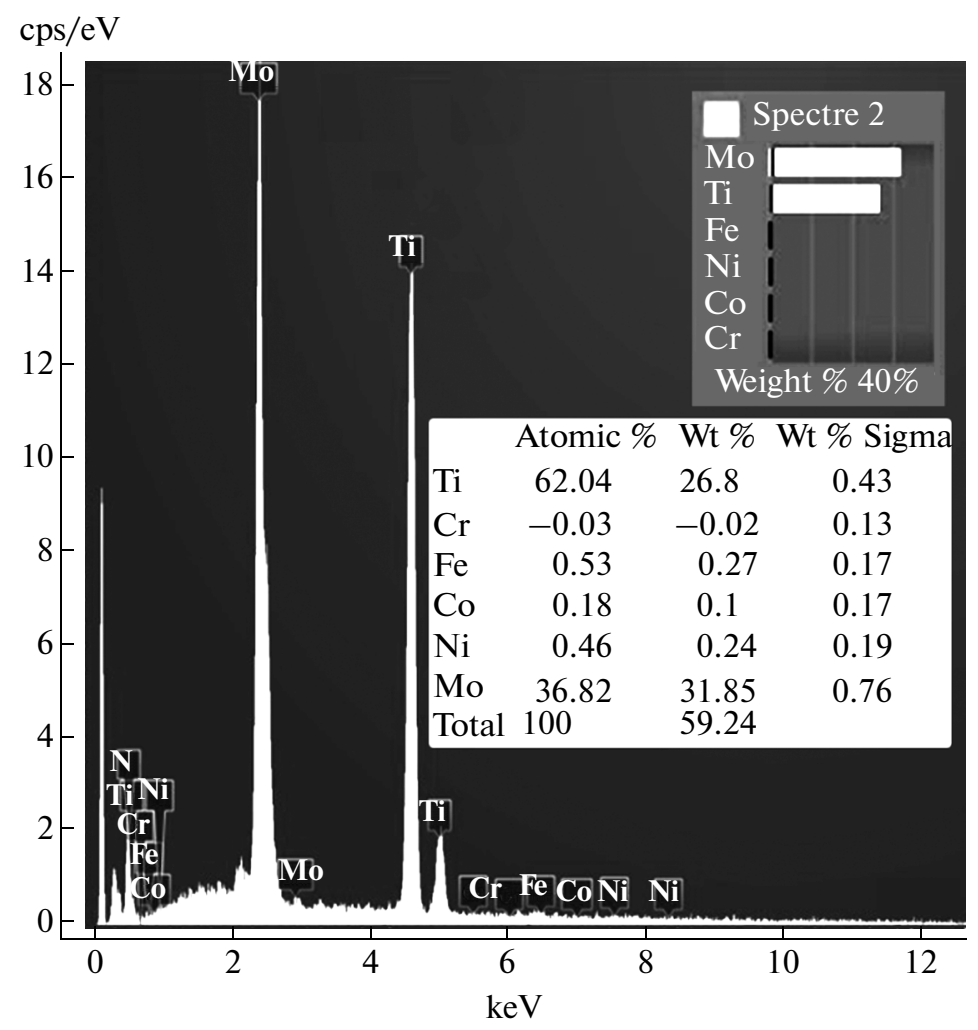

Fig. 1. Energy-dispersive spectrum of the sample with a multilayer nanocomposite coating with a period thickness of $10 \mathrm{~nm}$.

and determine their thickness. The degree of perfection of the texture $(\Delta \psi)$ was determined from the full width at half maximum of the diffraction line recorded during $\theta$-scanning. In the case of overlapping of the diffraction profiles, they were separated using the New_profile software for separating overlapping lines, which was developed at the National Technical University Kharkiv Polytechnic Institute. The volume fraction of the phases in the coating was calculated by a standard technique taking into account the integrated intensity and reflectance of a few lines of each of the phases. Analysis of the phase composition was conducted using the ASTM file-cabinet.

At a layer thickness of about $2 \mathrm{~nm}$, the coating exhibits the formation of a single phase with a fcc cubic lattice ( $\mathrm{NaCl}$ structural type) at a low substrate potential of $-40 \mathrm{~V}$. Deposition at the substrate potential increased to $-230 \mathrm{~V}$ leads to the formation of a two-phase system of TiN and high-temperature $\gamma$ $\mathrm{Mo}_{2} \mathrm{~N}$ with a phase ratio in $\mathrm{TiN} / \mathrm{MoN}$ of $90 / 10$, respectively. The occurrence of a two-phase state is caused by intense ion bombardment, which contributes to the nanograin size reduction and the beginning of formation of interfaces. This is accompanied by the formation of individual $\mathrm{Mo}_{2} \mathrm{~N}$ layers with a cubic lattice and, accordingly, the formation of an interface. In turn, the formation of individual $\mathrm{Mo}_{2} \mathrm{~N}$ layers with a cubic lattice and the formation of an interface lead to an increase in stresses in the TiN phase and in the period in the strained section. In this case, the coatings have a columnar structure [7,8].

An increase in the layer thickness to $10 \mathrm{~nm}$ results in the formation of a two-phase structural state with an average content of TiN and $\gamma-\mathrm{Mo}_{2} \mathrm{~N}$ cubic phases of 60 and $40 \mathrm{vol} \%$, which is close to the EDX-derived ratio of $\mathrm{Ti}$ and Mo concentrations of 62.3 and 36.8 at \%, respectively (Fig. 1).

Figure 2 shows a section of the nanostructured coating with visible alternating (nanoscale) layers of TiN (dark regions) and MoN (light regions), which are quite clear under this magnification.

The occurrence of a significant specific volume of interfaces owing to a high content of the second $\gamma-\mathrm{Mo}_{2} \mathrm{~N}$ phase is accompanied by the development of high compressive stresses in titanium nitride and the achievement of a maximum hardness of $32 \mathrm{GPa}$.

It is worth noting that the molybdenum-nitride layers contain only the $\gamma-\mathrm{Mo}_{2} \mathrm{~N}$ phase, while the $\beta-\mathrm{Mo}_{2} \mathrm{~N}$ phase is absent, although both phases can be formed in the case of vacuum arc deposition of the coating [2]. This can be attributed to the two-stage pattern of formation of the phase composition of nanostructured multilayer coatings [9-11, 13-15]. At the onset of growth of $\mathrm{Mo}_{2} \mathrm{~N}$, the determining factor for nucleation is the atomic sequence of the basic TiN lattice by local epitaxy. Thus, during growth of a molybdenumnitride layer, the cubic modification of $\gamma-\mathrm{Mo}_{2} \mathrm{~N}$ undergoes stabilization, which, under the action of 


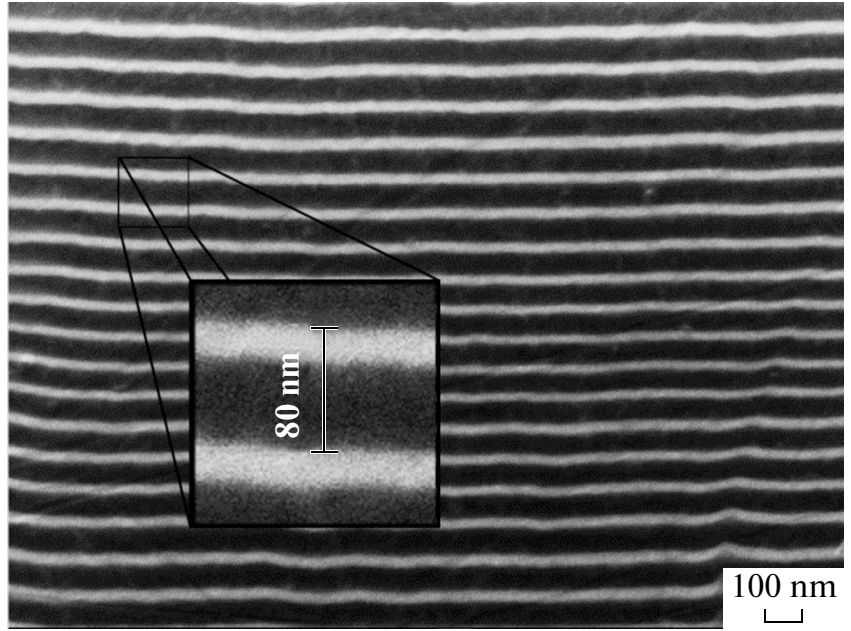

Fig. 2. Micrograph of a fragment of the section of the multilayer nanostructured $\mathrm{Ti}-\mathrm{Mo}-\mathrm{N}$ coating. The layer thickness is $40 \mathrm{~nm}$.

structural macrostresses upon the achievement of a relatively large thickness, is accompanied by the removal of macrodeformation and the formation of an interface $[9,10,15]$.

For the samples with a coating layer thickness of about $20 \mathrm{~nm}$ with thicker $\mathrm{TiN}$ and $\mathrm{Mo}_{2} \mathrm{~N}$ layers, the volume content of the phases is in fairly good agreement with the values expected according to EDX analysis: 70 at $\% \mathrm{TiN}$ and 30 at $\% \mathrm{Mo}_{2} \mathrm{~N}$. An increase in the layer thickness to $40 \mathrm{~nm}$ leads to an increase in the volume fraction of $\mathrm{Mo}_{2} \mathrm{~N}$ to $40 \%$, while the hardness has the lowest value (does not exceed $26 \mathrm{GPa}$, see Fig. 3a) and the Young modulus is $392 \mathrm{GPa}$ (Fig. 3b).

Analysis of tribological properties shows that roughness $R a$ achieves $0.3 \mu \mathrm{m}$ and the friction coefficient varies from 0.09 to 0.12 . The critical load (at which the coating begins to break down) is $42.5 \mathrm{~N}$ at a layer thickness of about $40 \mathrm{~nm}$ and achieves 61.0$64.8 \mathrm{~N}$ at a thickness of 10 and $2 \mathrm{~nm}$. Thus, the smaller the layer thickness, the higher the load; this suggests that, in the last-mentioned case, the nanograins are enveloped by a single nitride monolayer. Therefore, the strength of the nanocomposite increases by preventing grain boundary shearing (sliding). In terms of the Koehler model [9], valence charge transfer, nanograin size reduction, and a decrease in the entropy of mixing is a possible mechanism for increasing the hardness of these heterostructures [3, 8, 10-15]. The lowest wear was observed during deposition of layers with thicknesses of 2 and $10 \mathrm{~nm}$; it was 0.148 and $2.327 \times 10^{-5} \mathrm{~mm}^{3} \mathrm{~N}^{-1} \mathrm{~mm}^{-1}$ for the counterbody and the coating, respectively. Annealing of the samples to a temperature of $800^{\circ} \mathrm{C}$ in an oven under a vacuum of $10^{-2} \mathrm{~Pa}$ for $2 \mathrm{~h}$ leads to a decrease in the compressive stresses and a slight growth of nanograins to $10-15 \%$ (at most).
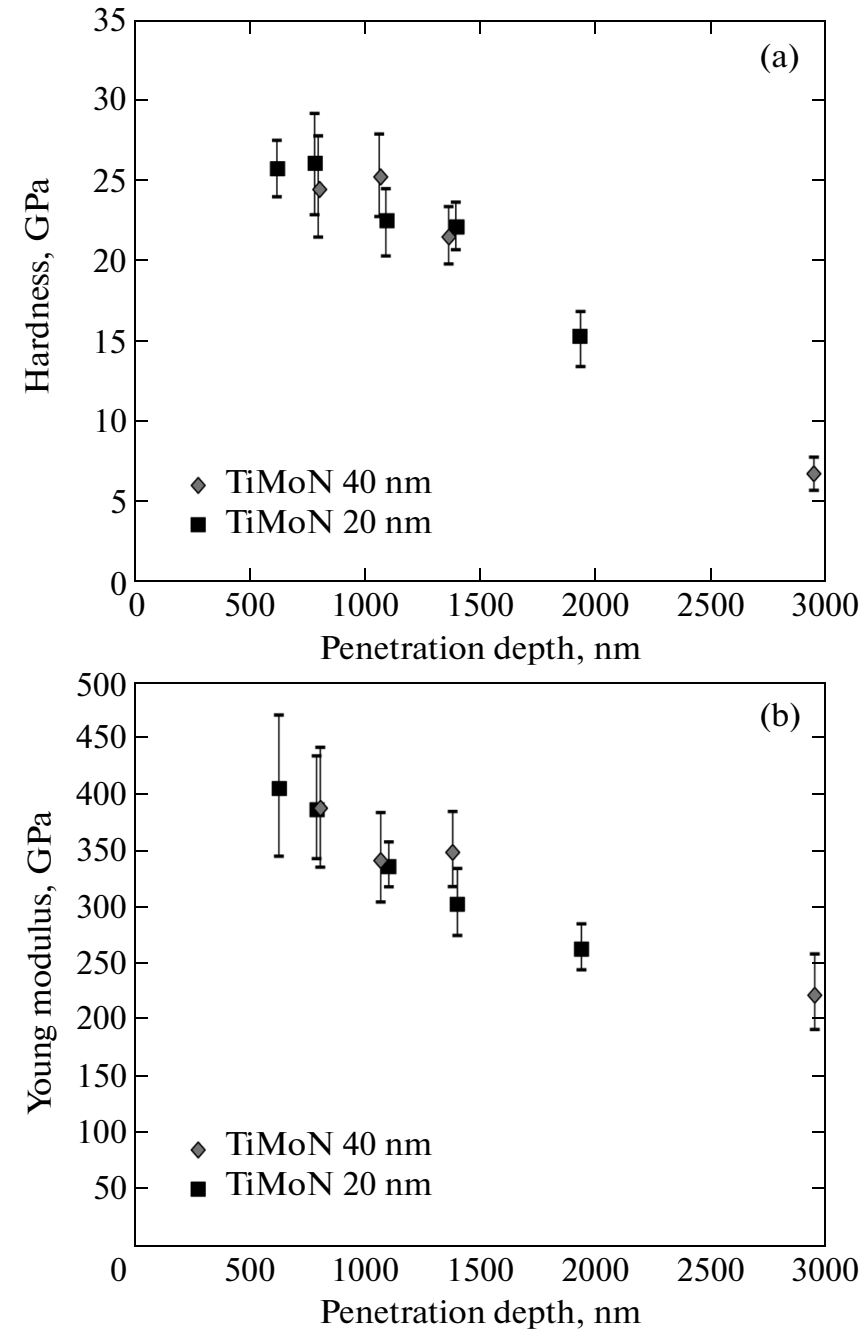

Fig. 3. Features of the microhardness of TiN/MoN: dependence of (a) microhardness $H$ and (b) Young modulus $E$ on the indentation depth at a layer thickness of 20 and $40 \mathrm{~nm}$.

Acknowledgments. This work was performed within the framework of a scientific and technical cooperation program with the University of Poitiers, France, and the integrated state budget programs "Development of Bases of Formation of Superhard Nanostructured Multicomponent Coatings with High Physicomechanical Properties" (no. 0112U001382) and "Physical Principles of Plasma Technologies for Complex Processing of Multicomponent Materials and Coatings" (no. 0113U000137s).

\section{REFERENCES}

1. M. K. Kazmanli, M. Urgen, and A. F. Cakir, Surf. Coat. Technol. 167, 77 (2003).

2. A. D. Korotaev, V. Yu. Moshkov, et al., Fiz. Mezomekh. 8 (5), 103 (2005).

3. A. D. Pogrebnyak, A. P. Shpak, N. A. Azarenkov, and V. M. Beresnev, Phys. Usp. 52, 29 (2009). 
4. A. D. Pogrebnjak, A. G. Ponomarev, A. P. Shpak, and Yu. A. Kunitskii, Phys. Usp. 55, 270 (2012).

5. A. D. Pogrebnjak, V. M. Beresnev, A. A. Dem'yanenko, V. S. Baidak, F. F. Komarov, M. V. Kaverin, N. A. Makhmudov, and D. A. Kolesnikov, Phys. Solid State 54, 1882 (2012).

6. S. Veprek, A. S. Argon, and R. F. Zhang, Philos. Mag. Lett. 87, 955 (2007).

7. J. Musil, Surf. Coat. Technol. 207, 50 (2012).

8. S. Veprek and M. G. J. Veprek-Heijman, Thin Solid Films 522, 274 (2012).

9. E. B. Bojko, F. F. Komarov, Cz. Karwat, et al., Vacuum 78, 241 (2005).
10. P. Zukowsky, F. F. Komarov, Cz. Karwat, et al., Vacuum 83, S204 (2009).

11. J. S. Koehler, Phys. Rev. B 2, 547 (1970).

12. Ya. A. Lyashenko, A. V. Khomenko, and L. S. Metlov, Tech. Phys. 55, 1193 (2010).

13. P. V. Zukowski, T. N. Koltunowicz, J. Partyka, et al., Vacuum 83, S280 (2009).

14. A. V. Khomenko and N. V. Prodanov, Condens. Matter Phys. 11 (4(56)), 615 (2008).

15. T. N. Koltunowicz, P. Zukowski, V. V. Fedotova, et al., Acta Phys. Pol. 120 (1), 39 (2011).

Translated by M. Timoshinina 